\title{
ENDOSCOPIC RELEASE OF RESISTANT PLANTAR FASCIOPATHY
}

\author{
By
Mohammed El-Sayed Ibrahim El-Nagar, Ahmed Abd El-Hamid Shamma and Mohammed Fathy El-Halawany \\ Department of Orthopedic Surgery, Faculty of Medicine, Al-Azhar University
}

\begin{abstract}
Background: Plantar fasciopathy is the most common cause of plantar heel pain. No enough evidence in literature strongly supports the effectiveness of any specific treatment for such conditions.

Objective: To assess the efficacy and safety of a modified surgical technique for endoscopic release of plantar fascia.

Patients and methods: A total of 29 feet in 25 patients with plantar fasciopathy for at least one year and resistant for at least two modalities of conservative treatment for six months were involved in this prospective study. All patients had been diagnosed clinically and the study was carried at the Department of Orthopedics, AL-Hussein University Hospital, Faculty of Medicine, Al-Azhar University in the period between December 2019 and September 2020.
\end{abstract}

Results: The mean AOFAS preoperative score had improved from 51.36 to 89.44 after six months follow-up. While The VAS score dropped from 85 preoperative to 12.6. Eighty four (84\%) of patients had satisfactory outcomes according to Roles and Madsuley criteria. No major complications were recorded.

Conclusion: Endoscopic plantar fascia release could be a viable alternative for management of chronic resistant plantar fasciopathy.

Keywords: Plantar fascia, plantar fasciopathy, Endoscopic release, Heel pain.

\section{INTRODUCTION}

Although the term plantar fasciitis is commonly used, plantar fasciopathy terminology is a better reflection of the underlying histology, which rarely includes inflammatory cells (Lemont et al., 2013).

The etiology of the disease is not clear. It can be the result of irritation because of the over-strain of the fascia (chronic micro injuries), which induces pathological deformations such as mucoid degeneration, reparative inflammation, then calcification (Abreu et al., 2013).
Plantar fasciitis is the most common injury of the plantar fascia. Up to $40 \%$ of the population suffers from painful feet problems, at least once during their life, and more than $10 \%$ of the population during their life suffers from heel pain that is caused by an inflammation in the proximal insertion of the plantar fascia (Oliver et al., 2012).

Apart from antero-posterior and standing lateral radiographs, sonography, 99m Tc-methylene diphosphonate bone scan and even MRI are recommended options for diagnosis and documentation (Neufeld and Cerrato, 2011). 
The choice of treatment for each individual case remains controversial and is based on the personal experience of the treating physician. There is little argument that conservative treatment is the treatment of choice. The scope of suggested conservative treatments includes multiple conservative pharmacological and therapeutic interventions (non-steroidal antiinflammatory drugs, heel pads or orthotics, physical therapy, night splints and corticosteroid injections) but none have proven to be effective, nor shown consistent results due to lack of welldesigned and well conducted comparative studies (Guijosa et al., 2011).

Most of the patients subsequently improve to the point of symptomatic satisfaction with one or more of the noninvasive interventions (Ogden et al., 2010).

Extracorporeal shock wave therapy (ESWT) is a non-invasive option for pain relief, the mechanism is unknown. However, it has been suggested that it may stimulate or reactivate the healing processes in musculoskeletal tissue (Tsai et al., 2011).

Platelets rich plasma (PRP) is derived from autologous blood and contains high concentration of growth factors necessary for tissue healing. The use of PRP in the treatment of plantar fasciopathy is a fairly recent and evolving concept (Ragab and Othman, 2012).

Many surgical approaches have been proposed, with varying degree of success. Surgical procedures include calcaneal drilling, calcaneal rotational osteotomy, isolated plantar fascia release from its insertion at the calcaneus, excision of the spur, medial calcaneal nerve or Baxter nerve neurolysis, and medial calcaneal nerve neurectomy (Cottom et al., 2016).

Endoscopic plantar fascia release has been reported as a viable, and possibly superior, alternative to established open procedures for the treatment of plantar fasciopathy. The majority of patients reported satisfaction with the endoscopic plantar fascia release and no long-term surgical complication (DiGiovanni et al., 2010).

The aim of the study was to evaluate the efficacy and safety of endoscopic surgical release of the plantar fascia as a minimally traumatic procedure for resistant plantar fasciitis.

\section{PATIENTS AND METHODS}

Twenty five patients who had chronic resistant heel pain for at least one year were enrolled in a prospective case series study conducted at the Department of Orthopedics, Al-Hussein University Hospital, Faculty of Medicine, Al-Azhar University, during the period between December 2019 and September 2020. Twenty two cases were females and three cases were males. The range of patient's age was between (25 and 59) years old.

\section{Inclusion criteria:}

Patients included in the study were adults more than 18 years old, presented by a single site heel pain with local pressure at the origin of the plantar fascia on the medial calcaneal tuberosity for at least one year, with failure of at least two lines of conservative treatment including non-steroidal anti-inflammatory drugs (NSAIDs), corticosteroid injections, physical therapy, exercise program 
(Achilles tendon and plantar fascia stretching exercises) and orthotic devices (heel cup, molded shoe insert or night splint) for at least 6 months.

\section{Exclusion criteria:}

Patients with pes planus, pes cavus, limb_length discrepancy, in-toeing, neuromuscular disorders, history of generalized poly-arthritis or prior heel surgery were not included in the study.

All patients were subjected to the following:

- History: Detailed history from each patient had been taken regarding age, gender, occupation, side involved, duration of symptoms, and number of steroids injection.

- Examination: Local examination for the involved side by inspection, palpation, neurological examination, special clinical tests and comparison with the other side. General examination to detect other causes of heel pain.

- Investigations: The diagnosis was based mainly on history and clinical examination. However, pre-operative $x$-ray of the calcaneus was obtained for all patients to document the presence of heel spur.

All Patients were assessed preoperatively by the following three scores:

1. Morning Pain: A visual analogue scale ranging from 0 (no pain) to 100 (maximal pain).

2. American Orthopedic Foot and AnkleHind-Foot Scale (AOFAS) (Ermutlu et al., 2018). It includes: pain (40 points), function (50 points) and alignment assessment (10 points).

3. Patient subjective assessment: patients assessed their overall condition according to the criteria of Roles and Maudsley (Akşahin et al., 2012) as follow:

1. Excellent: no pain, full movement and full activity.

2. Good: occasional discomfort, full movement and full activity.

3. Acceptable: some discomfort after prolonged activities.

4. Poor: pain-limiting activity.

* Success is defined as an excellent or good score based on Roles and Maudsley.

\section{Patient's education and consent:}

All patients were educated about the operation, the possible complications and results. Written informed consents were obtained and the study approved by the Local Ethical Committee.

\section{Operative technique:}

Surgery was performed under spinal anesthesia, in the supine position with the foot hanging outside the edge of the table. A pneumatic tourniquet was maintained on the thigh throughout the procedure. A medial portal was developed $1 \mathrm{~cm}$ away from the plantar skin along a vertical line passing through the posterior border of the medial malleolus with the foot in neutral position.

Using small blunt dissecting scissors, separate the subcutaneous fat creating a portal. A fascial elevator was then passed from the medial portal toward lateral side many times to create a subcutaneous 
tunnel, the roof of which was formed by the plantar fascia. A $5 \mathrm{~mm}$ cannula with a blunt tip trocar or a specific endoscopic sleeve was then inserted transversely into the subcutaneous tissue just inferior to the plantar fascia. A lateral portal was made in the lateral side where the trocar which slide inside the sleeve emerges.

The blunt trocar was passed from medial to lateral then the sleeve was introduced through the lateral portal over the trocar. Irrigation fluid was then connected, with the fluid inflow pressure between 50 and $60 \mathrm{mmHg}$. A30-degree $4.0 \mathrm{~mm}$ endoscope was inserted inside the cannula or sleeve showing the plantar fascial pad of fat. A $4.5 \mathrm{~mm}$ motorized incisor blade (shaver) was then used to debride the subcutaneous tissue until full visualization of the shiny fibers of the plantar fascia was possible. A standard scalpel blade No. 11or specific endoscopic scissor was then introduced through the medial portal to divide the full thickness of the medial half of the plantar fascia into two leaflets under direct visualization.

Full thickness release was achieved until visualization of abductor hallucis muscle fibers. The tunnel was then irrigated and each portal was sutured by one (3-0 prolene) stitch, Dressing and crepe bandage were then applied.

\section{Post-operative care:}

The following protocol was applied for all patients:

- Post operatively, patients had rest, limb elevation, cold compression and analgesics.

- Patients discharged on the same day or first day post-operative with oral antibiotics, analgesics and antiedematous drugs.

- Non weight bearing for two weeks then toe touch weight bearing progressing to full weight bearing according to tolerance.

- Dressing with normal saline and sterile dressing every 2-3 days.

- Removal of stitches after 10-14 days post-operative at the out-patient clinic.

- No specific exercises program was advised for patients.

\section{Follow up:}

The first follow up was after two weeks for removal of stitches and starting weight bearing. The patients then assessed for pain and function improvement after 4 weeks, 3months and 6months postoperative based on the following:

1. Morning Pain: a visual analogue scale ranging from 0 (no pain) to 100 (maximal pain).

2. American Orthopedic Foot and AnkleHind foot Scale (AOFAS) (71). It includes: pain (40 points), function (50 points) and alignment assessment (10 points).

3. Patient subjective assessment: patients assessed their overall condition compared to before treatment, according to the criteria of Roles and Maudsley (72) as follows:

1. Excellent: no pain, full movement and full activity.

2. Good: occasional discomfort, full movement and full activity.

3. Acceptable: some discomfort after prolonged activities. 
4. Poor: pain-limiting activity.

* Success is defined as an excellent or good score based on Roles and Maudsley.

\section{Statistical analysis:}

Data were statistically described in terms of mean, \pm standard deviation $( \pm \mathrm{SD})$, range or frequencies (number of cases) and percentiles when appropriate. Comparison of numerical variables between the different time periods was done using Freidman's test with posthoc multiple pairwise comparison tests.

$P$ value less than 0.05 was considered statistically significant. All statistical calculations were done using computer program SPSS (Statistical Package for the Social Sciences; SPSS Inc., Chicago, IL, USA) release 15 for Microsoft Windows (2010).

\section{RESULTS}

Twenty five patients who had chronic resistant heel pain for at least one year were enrolled in this prospective case series study. Twenty two cases were females and three cases were males. The range of patient's age was between ( 25 and 59) years old. Four cases had bilateral chronic heel pain and twenty one patients had a unilateral chronic heel pain (8 cases were left sided and 13 cases were right sided). The studied cases were distributed according to age, BMI, duration of symptoms (yr.) and number of steroid injections. The current study shows that the patients` age range from 25-59 years, morning heel pain and other symptoms of chronic plantar fasiopathy persisted for (1 to 3) years and most of patients were injected by (1 to 4) doses of corticosteroids. The studied cases were distributed according to gender, occupation, side involved and presence of calcaneal spur. The current study shows that the most of the patients were females, house wives, right sided and had a calcaneal spur (Table 1).

Table (1): Distribution of the studied cases according to age, BMI, duration of symptoms (yr.) and number of steroid injections, patients' gender, occupation, side involved and presence of calcaneal spur

\begin{tabular}{|c|c|c|c|c|c|}
\hline Distribution & $\begin{array}{c}\text { No. of } \\
\text { cases }\end{array}$ & Minimum & Maximum & Mean & $\begin{array}{c}\text { Standard } \\
\text { deviation }\end{array}$ \\
\hline Age & 25 & 25 & 59 & 41.12 & 8.126 \\
\hline BMI & 25 & 22.8 & 41.1 & 31.328 & 4.8279 \\
\hline $\begin{array}{c}\text { Symptom of } \\
\text { duration (yr.) }\end{array}$ & 25 & 1 & 3 & 1.875 & 1.537 \\
\hline $\begin{array}{c}\text { Number of steroids } \\
\text { inj. }\end{array}$ & 25 & 1 & 4 & 2.5 & 1.818 \\
\hline
\end{tabular}




\begin{tabular}{|c|l|c|c|}
\hline \multirow{4}{*}{ Gender } & & Frequency & Percentage \\
\cline { 2 - 4 } & Female & 22 & $88 \%$ \\
\cline { 2 - 4 } & Male & 3 & $12 \%$ \\
\cline { 2 - 4 } & Total & 25 & $100 \%$ \\
\hline \multirow{3}{*}{$\begin{array}{c}\text { Patients } \\
\text { occupation }\end{array}$} & $\begin{array}{l}\text { House } \\
\text { waives }\end{array}$ & 19 & $76 \%$ \\
\cline { 2 - 4 } & Workers & 6 & $24 \%$ \\
\cline { 2 - 4 } & Total & 25 & $100 \%$ \\
\hline \multirow{3}{*}{ Side involved } & Left & 8 & $24 \%$ \\
\cline { 2 - 4 } & Right & 13 & $44 \%$ \\
\cline { 2 - 4 } & Bilateral & 4 & $32 \%$ \\
\hline \multirow{3}{*}{ Calcaneal spur } & No & 3 & $12 \%$ \\
\cline { 2 - 4 } & Yes & 22 & $88 \%$ \\
\cline { 2 - 4 } & Total & 25 & $100 \%$ \\
\hline
\end{tabular}

The results of the current study are encouraging, it shows improvement in the morning pain according to the visual analogue scale (VAS).The mean pre- operative (VAS) score was 85 (range, 7097), dropped to 12.60 (range, 0-47) 6 months post operatively (Table 2).

Table (2): Visual analogue scale (VAS) at baseline, 4 weeks, 3 months and 6 months post-operatively

\begin{tabular}{|c|c|c|c|c|c|}
\hline Das Data & $\begin{array}{c}\text { No.of } \\
\text { cases }\end{array}$ & Minimum & Maximum & Mean & $\begin{array}{c}\text { Standard } \\
\text { deviation }\end{array}$ \\
\hline Base line & 25 & 70 & 97 & 85.00 & 7.130 \\
\hline 4 weeks & 25 & 14 & 91 & $47.84^{*}$ & 18.927 \\
\hline 3 months & 25 & 0 & 55 & $26.56^{*}$ & 16.109 \\
\hline 6 months & 25 & 0 & 47 & $12.60^{*}$ & 11.431 \\
\hline
\end{tabular}

* Significantly different from the precedent time period $(\mathrm{P}<0.0001)$.

The studied cases were distributed according to parameters of American Orthopedic Foot and Ankle-Hind-foot Scale (AOFAS) at base line, 4 weeks, 3 months and 6 months post-operatively. The current study shows relief of morning pain post-operatively and improvement of function and alignment (Table 3). 
Table (3): Distribution of the studied cases according to American Orthopedic Foot and Ankle-Hind-foot Scale (AOFAS) at base line, 4 weeks, 3 months and 6 months post-operatively.

\begin{tabular}{|c|c|c|c|c|c|c|}
\hline \multicolumn{2}{|c|}{$\begin{array}{r}\text { American Orthopedic Foot } \\
\text { and Ankle-Hind-foot } \\
\text { Scale (AOFAS) }\end{array}$} & \multirow{2}{*}{$\begin{array}{l}\text { Min. } \\
20 \\
\end{array}$} & \multirow{2}{*}{$\begin{array}{c}\text { Max. } \\
40\end{array}$} & \multirow{2}{*}{$\begin{array}{l}\text { Mean } \\
32.00 * \\
\end{array}$} & \multirow{2}{*}{$\begin{array}{c}\text { Standard } \\
\text { Deviation } \\
5.000 \\
\end{array}$} & \multirow{2}{*}{$\begin{array}{c}\begin{array}{c}\mathrm{P}- \\
\text { value }\end{array} \\
0.049 \\
\end{array}$} \\
\hline \multirow{4}{*}{ Pain } & Base Line & & & & & \\
\hline & 4wk. & 20 & 40 & $29.60 *$ & 5.385 & 0.035 \\
\hline & $3 \mathrm{~m}$. & 0 & 30 & $25.20 *$ & 7.141 & 0.026 \\
\hline & $6 \mathrm{~m}$. & 0 & 20 & 8.00 & 10.000 & 0.0165 \\
\hline \multirow{4}{*}{$\begin{array}{c}\text { Activity } \\
\text { Limitation }\end{array}$} & base line & 4 & 10 & $8.92 *$ & 1.706 & 0.051 \\
\hline & 4wk. & 4 & 10 & $7.96^{*}$ & 2.071 & 0.046 \\
\hline & $3 m$. & 4 & 7 & $5.56^{*}$ & 1.530 & 0.0156 \\
\hline & $6 \mathrm{~m}$. & 0 & 4 & 2.56 & 1.960 & 0.0245 \\
\hline \multirow{4}{*}{$\begin{array}{c}\text { Maximum } \\
\text { walking } \\
\text { distance }\end{array}$} & base line & 2 & 5 & 3.48 & 1.085 & 0.032 \\
\hline & 4wk. & 2 & 5 & $4.32 *$ & 0.852 & 0.048 \\
\hline & $3 \mathrm{~m}$. & 4 & 5 & $4.80 *$ & 0.408 & 0.021 \\
\hline & $6 \mathrm{~m}$. & 4 & 5 & 4.88 & 0.332 & 0.037 \\
\hline \multirow{4}{*}{$\begin{array}{l}\text { Walking } \\
\text { Surfaces }\end{array}$} & base line & 0 & 3 & 2.04 & 1.428 & 0.055 \\
\hline & 4wk. & 0 & 5 & $3.28 *$ & 1.061 & 0.025 \\
\hline & $3 \mathrm{~m}$. & 0 & 5 & $3.76^{*}$ & 1.268 & 0.043 \\
\hline & $6 \mathrm{~m}$. & 3 & 5 & 4.12 & 1.013 & 0.049 \\
\hline \multirow{4}{*}{$\begin{array}{c}\text { Gait } \\
\text { Abnormalities }\end{array}$} & base line & 4 & 8 & 7.52 & 1.327 & 0.035 \\
\hline & 4wk. & 4 & 8 & $6.88^{*}$ & 1.833 & 0.027 \\
\hline & $3 \mathrm{~m}$. & 0 & 8 & $5.76^{*}$ & 2.332 & 0.016 \\
\hline & $6 \mathrm{~m}$. & 0 & 8 & 3.52 & 2.104 & 0.032 \\
\hline \multirow{4}{*}{$\begin{array}{l}\text { Sagittal } \\
\text { Motion }\end{array}$} & base line & 4 & 10 & 8.92 & 1.706 & 0.037 \\
\hline & 4 weeks & 4 & 7 & 5.56 & 1.530 & 0.028 \\
\hline & 3 months & 3 & 9 & 4.47 & 1.013 & 0.045 \\
\hline & 6months & 5 & 10 & 7.20 & 1.154 & 0.058 \\
\hline \multirow{4}{*}{$\begin{array}{c}\text { Hind foot } \\
\text { Motion }\end{array}$} & base line & 3 & 6 & 5.76 & 0.831 & 0.034 \\
\hline & 4wk. & 3 & 7 & 5.93 & 0.640 & 0.025 \\
\hline & $3 \mathrm{~m}$. & 4 & 7 & 6.00 & 1.100 & 0.040 \\
\hline & $6 \mathrm{~m}$. & 4 & 8 & 6.13 & 1.120 & 0.051 \\
\hline \multirow{4}{*}{$\begin{array}{l}\text { Ankle- Hind } \\
\text { foot stability }\end{array}$} & base line & 2 & 5 & 3.48 & 1.085 & 0.035 \\
\hline & 4wk. & 2 & 5 & $4.32 *$ & 0.852 & 0.027 \\
\hline & $3 m$. & 4 & 5 & $4.80^{*}$ & 0.408 & 0.046 \\
\hline & $6 \mathrm{~m}$. & 4 & 5 & 4.88 & 0.332 & 0.035 \\
\hline \multirow{4}{*}{ Alignment } & base line & 0 & 4 & 2.56 & 1.960 & 0.018 \\
\hline & 4wk. & 4 & 7 & $5.56^{*}$ & 1.530 & 0.015 \\
\hline & $3 m$. & 4 & 10 & $7.96^{*}$ & 2.071 & 0.043 \\
\hline & $6 \mathrm{~m}$. & 4 & 10 & $8.92 *$ & 1.706 & 0.024 \\
\hline \multirow{4}{*}{$\begin{array}{l}\text { AOFAS total } \\
\text { Score }\end{array}$} & base line & 33 & 72 & 51.36 & 14.373 & 0.027 \\
\hline & 4wk. & 41 & 87 & $75.88^{*}$ & 10.576 & 0.035 \\
\hline & $3 \mathrm{~m}$. & 64 & 100 & $85.00 *$ & 8.765 & 0.042 \\
\hline & $6 \mathrm{~m}$. & 67 & 100 & $89.44 *$ & 7.741 & 0.031 \\
\hline
\end{tabular}

* Significantly different from the precedent time period. 
The studied cases were distributed according to criteria of Roles and Maudsley at base line, 4 weeks, 3 months and 6 months post operatively. The current study shows improvement of activities and range of motion in most of cases post operatively (Table 4).
At base line: all patients had poor criteria. Four weeks, three months and six months post-operatively shows improvement of activities and range of motion (Table 4).

Table (4): Distribution of the studied cases according to criteria of Roles and Maudsley at 4 weeks post-operative, Maudsley at 3 months post-operative and Maudsley at 6 months post-operative

\begin{tabular}{|c|c|c|c|c|}
\hline Parameters Data & & \multicolumn{2}{|c|}{ Frequency } & Percent \\
\hline \multirow{4}{*}{4 weeks post-operative } & Good & \multicolumn{2}{|c|}{7} & $28 \%$ \\
\hline & Acceptable & \multicolumn{2}{|c|}{13} & $52 \%$ \\
\hline & Poor & \multicolumn{2}{|c|}{5} & $20 \%$ \\
\hline & Total & \multicolumn{2}{|c|}{25} & $100 \%$ \\
\hline \multirow{5}{*}{3 months post-operative } & Excellent & \multicolumn{2}{|c|}{2} & $8 \%$ \\
\hline & Good & \multicolumn{2}{|c|}{15} & $60 \%$ \\
\hline & Acceptable & \multicolumn{2}{|c|}{7} & $28 \%$ \\
\hline & Poor & \multicolumn{2}{|c|}{1} & $4 \%$ \\
\hline & Total & \multicolumn{2}{|c|}{25} & $100 \%$ \\
\hline \multirow{5}{*}{6 months post-operative } & Excellent & \multicolumn{2}{|c|}{6} & $24 \%$ \\
\hline & Good & \multicolumn{2}{|c|}{15} & $60 \%$ \\
\hline & Acceptable & \multicolumn{2}{|c|}{3} & $12 \%$ \\
\hline & Poor & \multicolumn{2}{|c|}{1} & $4 \%$ \\
\hline & Total & \multicolumn{2}{|c|}{25} & $100 \%$ \\
\hline $\begin{array}{ll}\text { Roles } \\
\text { and Maudsley }\end{array}$ & Base line & 4weeks & 3months & 6months \\
\hline Excellent & $\mathbf{0}$ & $\mathbf{0}$ & 2 & 6 \\
\hline Good & $\mathbf{0}$ & 7 & 15 & 15 \\
\hline Acceptable & $\mathbf{0}$ & 13 & 7 & 3 \\
\hline Poor & 25 & 5 & 1 & 1 \\
\hline Total & 25 & 25 & 25 & 25 \\
\hline
\end{tabular}

The success rates (number of patients who achieved good and excellent scores in the Roles and Maudsley criteria were 7 $(28 \%)$ at 4 weeks post-operatively, increased to $17(68 \%)$ at 3 months postoperatively and to $21(84 \%)$ at 6 months post-operatively.

\section{Complications of the study:}

No major side effects were observed in our study. Two patients developed paresthesia along the medial aspect of the hind-foot which improved later on follow up. Superficial infection was recorded with one patient and it was improved with oral antibiotics. Another two patients developed post-operative swelling that resolved with foot elevation. We noted no post-operative foot deformities or major changes in the arches of those who had surgery.

\section{DISCUSSION}


The results of the current study are encouraging, it showed improvement in the morning pain according to the visual analogue scale (VAS). The mean preoperative (VAS) score was 85 (range, 7097), dropped to 12.60 (range, 0-47) 6 months post operatively. This difference was statistically significant.

The success rates (number of patients who achieved good and excellent scores in the Roles and Maudsley criteria were $28 \%$ at 4 weeks, increased to $68 \%$ at 3 months and $84 \%$ at 6 months post-operatively.

The results in the current study were comparable with those of previously published reports on endoscopic plantar fascia release. Regarding the technique described in the current study, it was simple, economic, not technically demanding and did not need special instruments. Visualization was better if the endoscope introduced through the medial portal unlike previously described techniques. Plantar fasciotomy is done to reduce the mechanical overload in the affected area. In the current study, we didn't do fascial release only like the previously described techniques (El Shazly and El Beltagy, 2010). We also debrided the pathological tissue at the fascial origin and the inflamed periosteum using the motorized incisor blade. This was expected to improve the final results.

It was found that, regardless of the surgical technique (endoscopic or open release), lateral column symptoms were more likely to result when more than $50 \%$ of the plantar fascia was released (Cheung et al., 2011). This agreed with the results of the current study in which only 50\% release was done and the lateral column symptoms were not recorded. Also, it is well documented that excision of the spur is not a part of the usual surgical treatment for plantar fasciopathy (Young et al., 2011). In the current study, the heel spur was not removed in any patient. Meanwhile, satisfactory results were reported. The procedure done in the current study did not include decompression of the nerve to abductor digitiminimi (Baxter nerve).

Cole et al. (2013) found that the average distance between the site of release and the lateral plantar nerve and the nerve to the abductor digitiminimi was 10.5 and $12.3 \mathrm{~mm}$ respectively. Moreover, Crawford (2011) showed that reliable landmarks could allow a safe division of the plantar fascia. The reference line used in the current study was the posterior border of the medial malleolus and $1 \mathrm{~cm}$ from the plantar skin.

Regarding to the complications and side effects of current study, one patient had poor outcomes and three patients had acceptable outcomes after 6 months of follow up which was considered failure, We postulated that failure to lack of treatment of the main cause of pain in the plantar fasciopathy and not to the technique itself. There are multiple causes of pain in the plantar fasciopathy such as calcaneal periostitis, the heel spur and entrapment of the nerve to abductor digitiminimi (Baxter nerve) (Cole et al., 2013).

No major side effects were observed in our study. Two patients developed paresthesia along the medial aspect of the hind-foot which improved later on follow up. Super facial infection was recorded with one patient and it was improved with oral antibiotics. Another two patients 


\section{MOHAMMED EL-NAGAR et al.,}

developed post-operative swelling that resolved with foot elevation.

Limitation of the current study included the small sample size made statistical analysis of the data difficult and short follow up period in comparison with other studies (Nery et al., 2013) which had longer follow-up and lack of comparison group. We did not measure the duration for return to work because most of the patients enrolled in this current study were housewives. We choose the widely used American Orthopedic Foot and AnkleHind-foot Scale to allow comparison of the data. However, our limitation was with the translation of AOFAS score which has not been cross-culturally adapted.

\section{CONCLUSION}

The procedure is encouraging and could be a viable alternative for management of chronic resistant plantar fasciopathy. It is a safe, effective, simple, economic, not technically demanding and does not need special instruments.

\section{REFERENCES}

1. Abreu MR, Chung $C B$ and Mendes $L$. (2013): Plantar calcaneal enthesophytes: new observations regarding sites of origin based on radiographic, MR imaging, anatomic, and paleopathologic analysis. Skeletal Radiol., 32: $13-21$.

2. Akşahin E, Doğruyol D, Yüksel HY, Hapa $O$, Doğan $O$, Celebi $L$ andBiçimoğlu A.(2012): The comparison of the effect of corticosteroids and platelet-rich plasma (PRP) for the treatment of plantar fasciitis. Arch Orthop Trauma Surg., 132(6):781-5.

3. Cheung JTM, An KN and Zhang M. (2011): Consequences of partial and total plantar fascia release: a finite element study. Foot \&Ankle International, 27(2): 125-132.

4. Cole C, Seto C and Gazewood J (2013): Plantar Fasciitis: Evidence-Based Review of
Diagnosis and Therapy. American Family Physician, 72(11):2237-42.

5. Cottom JM, MakerJM, RichardsonP and BakerJS (2016): Endoscopic debridement for treatment of chronic plantar fasciitis: an innovative technique and prospective study of 46 consecutive patients J Foot Ankle Surg., 5: 748-752.

6. Crawford R. (2011): Diagnosis and treatment of plantar fasciitis. AmFam Physician, 84(6): 676-82.

7. DiGiovanni BF, Nawoczenski DA, Lintal ME, Moore EA, Murray JC, Wilding GE andBaumhauer JF (2010): Tissue-specific plantar fascia-stretching exercise enhances outcomes in patients with chronic heel pain. The Journal of Bone \& Joint Surgery, 85(7): 1270-1277.

8. El Shazly O and El Beltagy A. (2010): Endoscopic plantar fascia release, calcaneal drilling and calcaneal spur removal for management of painful heel syndrome. The Foot, 20(4): 121-125.

9. Ermutlu C, Aksakal M, Gümüştaş A, Özkaya G, Kovalak E andÖzkan Y. (2018): Thickness of plantar fascia is not predictive of functional outcome in plantar fasciitis treatment. Acta Orthop Traumatol Turc., 52(6):442-446.

10. Guijosa AL, Muñoz IOM, de La Fuente ME andCura-Ituarte P. (2011): Plantar fasciitis: evidence-based review of treatment. ReumatologíaClínica (English Edition), 3(4): 159-165.

11. Lemont $\mathrm{H}$, Ammirati $\mathrm{KM}$ andUsen $\mathrm{N}$. (2013): Plantar fasciitis: a degenerative process (fasciosis) without inflammation. Journal of the American Podiatric Medical Association, 93(3): 234-237.

12. Nery C, Raduan F, Mansur N, Baunfeld D, Del Buono A andMaffulli N. (2013): Endoscopic approach for plantar fasciopathy: a long-term retrospective study. IntOrthop., 37:1151-1156.

13. Neufeld SK andCerrato $R$ (2011): Plantar fasciitis: evaluation and treatment. J Am Acad Orthop Surg., 16:338-346. 
14. Ogden JA, Alvarez R, Levitt R, Cross GL and Marlow M. (2010): Shock wave therapy for chronic proximal plantar fasciitis. Clinical Orthopaedics and Related Research, 387: 4759.

15. Oliver M, Antje ES, Ralph $M$ and Michael HS. (2012): Radiotherapy for non-malignant disorders. Springer, Pp. 978.

16. Ragab EMS and Othman AMA (2012): Platelets rich plasma for treatment of chronic plantar fasciitis. Archives of Orthopaedicand Trauma Surgery, 132(8): 1065-1070.

17. Tsai WC, Hsu CC, Chen CP, Chen MJ, Yu TY and Chen YJ. (2011): Plantar fasciitis treated with local steroid injection: comparison between sonographic and palpation guidance. Journal of Clinical Ultrasound, 34(1): 12-16.

18. Young CC, Rutherford DS and Niedfeldt MW (2011): Treatment of plantar fasciitis. AmFam Physician, 63(3):467-74. 


\section{علاج إلتهاب اللفافة الأخمصية المستعصية بالمنظار

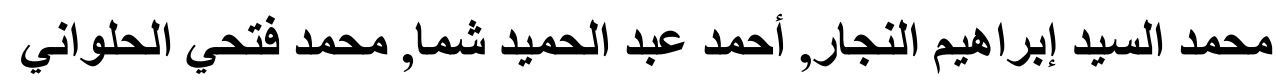
قسم جراحة العظام, كلية الطب، جامعة الأزهر

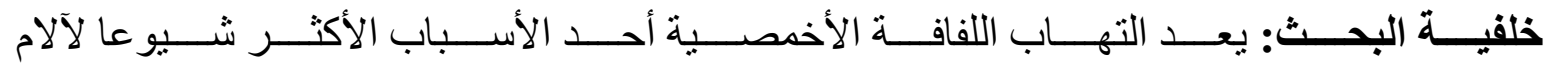

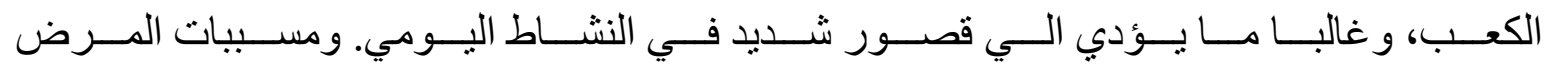

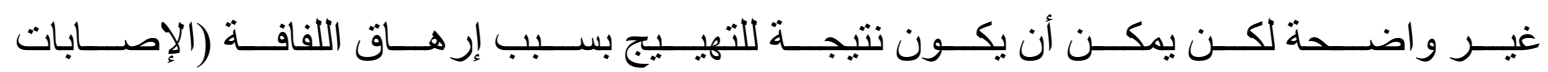

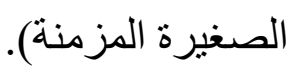

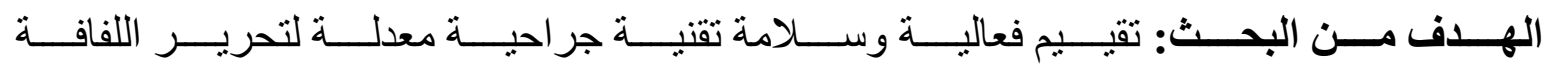

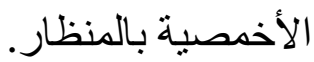

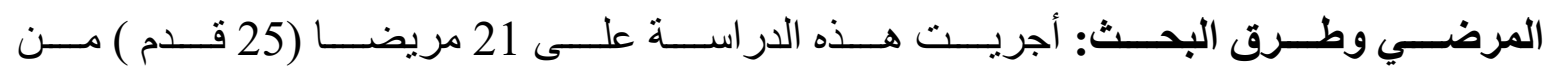

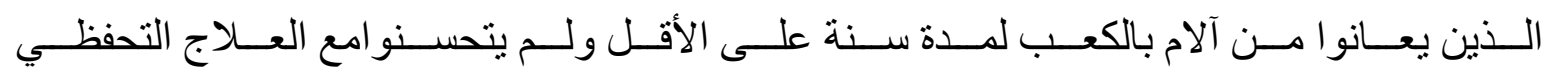

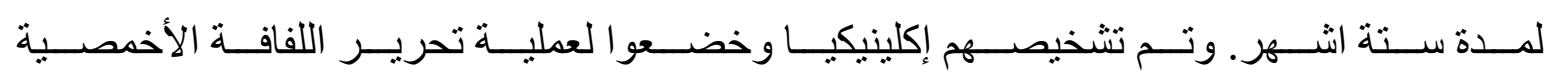
بالمنظار بطريقة جراحية معدلة.

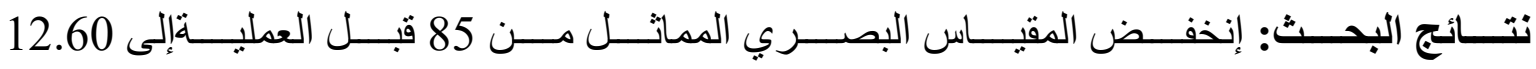

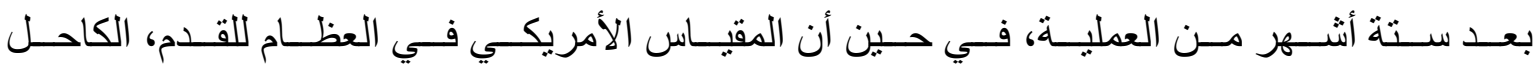

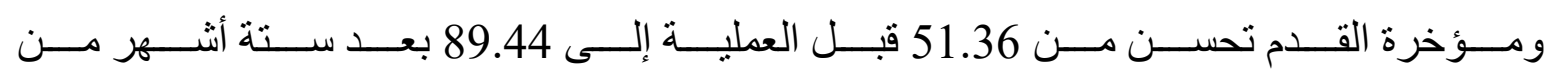
العملية. وكان معدل النجاح 84٪ وفقا لمعيير رولز ومودسلي.

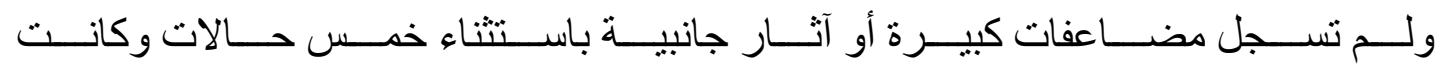

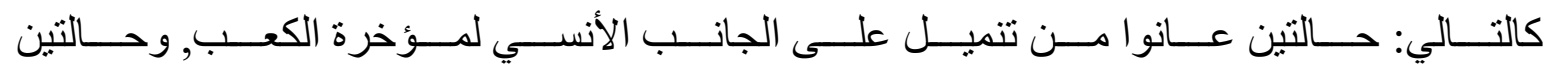

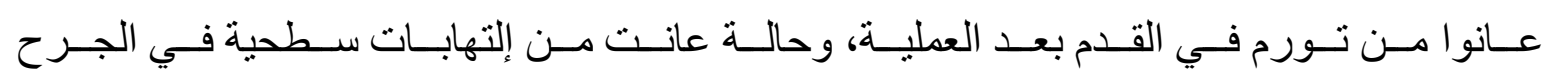
وجميعهم قد تم تحسنهم مع المتابعة.

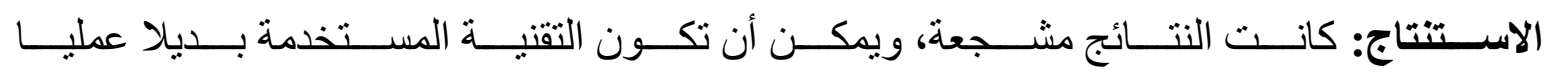

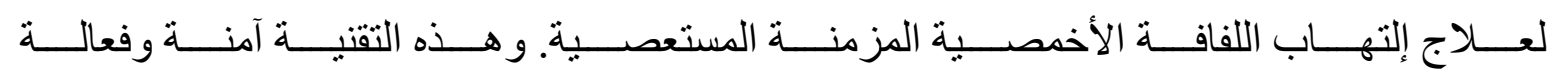
وبسيطة وغير مكلفة ماديا، و لاتتطلب تقنيات معينة أو أدوات خاصة. 